UDC 613.6.027

DOI: $10.21668 /$ health.risk/2020.4.03.eng

Research article

\title{
METHODICAL APPROACHES TO ASSESSING CATEGORIES OF OCCUPATIONAL RISK PREDETERMINED BY VARIOUS HEALTH DISORDERS AMONG WORKERS RELATED TO OCCUPATIONAL AND LABOR PROCESS FACTORS
}

\author{
N.V. Zaitseva ${ }^{1}$, P.Z. Shur ${ }^{1}$, V.B. Alekseev ${ }^{1}$, A.A. Savochkina ${ }^{2}$, \\ A.I. Savochkin ${ }^{3}$, E.V. Khrushcheva ${ }^{1}$ \\ ${ }^{1}$ Federal Scientific Center for Medical and Preventive Health Risk Management Technologies, 82 Monastyrskaya Str., \\ Perm, 614045, Russian Federation \\ ${ }^{2}$ Perm National Research Polytechnic University, 29 Komsomolskiy Ave., Perm, 614990, Russian Federation \\ ${ }^{3}$ National Research University «Higher School of economics», 20 Myasnitskaya Str., Moscow, 101000, \\ Russian Federation
}

If we want to assess occupational risks predetermined by various health disorders among workers related to occupational factors and labor process factors, we need to examine whether additional methods can be applied here; these methods should allow not only quantitative determination of occupational risk but also its adequate categorizing. A procedure for risk assessment based on fuzzy sets analysis can be considered and applied for the matter.

Suggested methodical approaches to occupational risk assessment based on this procedure involve step-by-step accomplishment of the following stages: determining fuzzy figures corresponding to preset occupational risk levels; preparing initial data (numeric characteristics of occupational risk) for calculations; probabilistic assessment whether a numeric characteristic of occupational risk belongs to fuzzy numbers; and estimated probability of belonging of occupational risk numeric characteristic. A basic instrument for implementing the procedure is determining a membership function for a trapezoid fuzzy number that estimates whether determined risk assessments belong to a specific risk category.

We suggested a scale for assessing occupational risk levels, starting from negligible $\left(0-1 \cdot 10^{-4}\right)$ to extremely high $\left(3 \cdot 10^{-1}-1\right)$ and corresponding boundaries of trapezoid fuzzy interval (four figures that define a trapezoid number).

The procedure was tested in a situation when occupational diseases (sensorineural hearing loss), work-related diseases (arterial hypertension), and their combinations were revealed under exposure to noise equal to $85 \mathrm{dBA}$; the tests allowed establishing that membership functions were equal to 1 for all risk levels determined as per results obtained via epidemiologic research.

Key words: occupational risk, risk categories, permissible risk, noise factor, labor process, occupational factors, fuzzy sets, trapezoid fuzzy number.

To preserve and develop labor resources is a priority task in providing national safety and securing development of any state. Up to 2035 economy in Russia is going to develop in a situation when there is depopulation in the country and it predetermines certain peculiarities related to labor potential development and a necessity to use it more efficiently. In such conditions state policy should be aimed at mobilizing all available resources that can help

(C) Zaitseva N.V., Shur P.Z., Alekseev V.B., Savochkina A.A., A.I. Savochkin, Khrushcheva E.V., 2020

Nina V. Zaitseva - Academician of the Russian Academy of Sciences, Doctor of Medical Sciences, Professor, Scientific Director (e-mail: znv@fcrisk.ru; tel.: +7 (342) 237-25-34; ORCID: https://orcid.org/0000-0003-2356-1145).

Pavel Z. Shur - Doctor of Medical Sciences, Academic Secretary (e-mail: shur@fcrisk.ru; tel.: +7 (342) 238-33-37; ORCID: https://orcid.org/0000-0001-5171-3105).

Vadim B. Alekseev - Doctor of Medical Sciences, Director (e-mail: alekseev@fcrisk.ru; tel.: +7 (342) 236-32-70; ORCID: https://orcid.org/0000-0001-8997-5493).

Anna A. Savochkina - Senior lecturer at the Higher Mathematics Department (e-mail: aidas_76@mail.ru; tel.: +7 (342) 239-16-97; ORCID: https://orcid.org/0000-0003-2591-6632).

Andrei I. Savochkin - Student (e-mail: savochkin.andrei2014@gmail.com; tel.: +7 (992) 237-16-56; ORCID: https://orcid.org/0000-0002-3591-2718).

Ekaterina V. Khrushcheva - Senior researcher acting as a Head of the Laboratory for Risk Management Methods and Technologies (e-mail: zem@fcrisk.ru; tel.: +7 (342) 238-33-37; ORCID: https://orcid.org/0000-0003-2107-8993). 
preserve population [1]. Reduction in risks for life and health caused by work tasks performance, in other words, occupational risks, is a way to preserve employable population [2-4].

Nowadays, there is a priori (preliminary) occupational risk assessment that involves using risk categories determined as per results obtained via hygienic assessment of working conditions (working conditions categories) and a posteriori (ultimate) one performed as per medical and biological criteria ${ }^{1,2}$. The most adequate results can be obtained via a posteriori assessment in case it is based on data obtained via epidemiologic research on workers' health. And here one should take into account that probably both occupational diseases and work-related ones might occur and develop.

Russian legislation defines working conditions as a set of occupational factors that influence workers' capacity and health ${ }^{3}$. However, methodical approaches to occupational risk assessment mostly involve analyzing risks caused by impacts exerted by specific risk factors whereas workers are usually exposed to simultaneous intensive effects produced by heterogeneous factors $[5,6]$. At the same time, we should take into account that an effect produced by a given occupational factor may result in occupational risks related to several diseases, both occupational and work-related ones [7-10]. Given that, assessment of occupational risk related to different health disorders among workers and caused by a set of occupational factors and factors related to labor process requires certain study on whether it is possible to apply additional procedures that allow not only quantitative determination of occupational risks but also their adequate categorizing. Risk assessment procedure based on fuzzy set analysis can be considered as a relevant one for the matter [11].
Fuzzy logic theory (or fuzzy set theory) is a new probabilistic approach to describing processes which involve uncertainty making it difficult to apply precise quantitative procedures and approaches [12].

Use of elements taken from fuzzy set theory allows assessing conditions of multicomponent negative exposure producing multiple negative effects including damage to health [13-16]. And here key parameters are estimated not with point values but with probabilistic interval ones that are characterized with a membership function showing belonging to a range of scaled parameters.

Fuzzy modeling allows including qualitative variables into analysis and operating with fuzzy initial data; modeling complicated dynamic situations quite rapidly and comparing them with preset precision. All this completely satisfies requirements to analyzing influence exerted by adverse occupational factors and working conditions on workers' health and to occupational risk assessment.

Use of fuzzy set procedures has certain advantages since in case of necessity it allows including quantitative variables in to analysis, operating fuzzy initial data and linguistic criteria, modeling complicated dynamic systems quite rapidly and comparing them with preset precision, overcoming drawbacks and limitations that can be found in existing risk assessment procedures. But still, there are certain drawbacks, primarily, a necessity to use specific software as well as a limited number of experts who are able to work with it [17].

Hygienic assessment of occupational factors, factors related to labor process, and exposure to them usually involves using both quantitative properties (for chemical or physical factors) and qualitative ones (for labor hardness and intensity). It also includes determining risk categories for calculated levels of risk

${ }^{1}$ G 2.2.2006-05. Guide on hygienic assessment of occupational factors and factors related to labor process Criteria and classification of working conditions. KODEKS: an electronic fund for legal and reference documentation. Available at: http://docs.cntd.ru/document/1200040973 (18.10.2020) (in Russian).

${ }^{2} \mathrm{G}$ 2.2.1766-03. Guide on assessing occupational health risks for workers. Organization and methodical grounds principles, and assessment criteria. KODEKS: an electronic fund for legal and reference documentation. Available at: http://docs.cntd.ru/document/901902053 (18.12.2020) (in Russian).

${ }^{3}$ RF Labor Code, Clause 209. Basic concepts. KonsultantPlus. Available at: http://www.consultant.ru/document/cons doc_LAW_34683/78f36e7afa535cf23e1e865a0f38cd3d230eecf0/ (18.12.2020) (in Russian). 
caused by simultaneous exposure to a set of occupational factors that are able to lead to several health disorders among workers; to do that, new probabilistic procedures for occupational risk categorizing can be quite useful. And fuzzy set procedure seems quite relevant for the matter.

Our research goal was to develop methodical approaches with the use of fuzzy set theory elements to assessing occupational risks related to different health disorders and their combinations among workers caused by negative effects produced by exposure to occupational factors and factors related to labor process.

Data and methods. Suggested methodical approaches included the following stages:

- determining fuzzy figures corresponding to preset occupational risk levels;

- preparing initial data (numeric characteristics of occupational risk) for calculations;

- probabilistic assessment whether a numeric characteristic of occupational risk belongs to fuzzy numbers;

- estimated probability of occupational risk numeric characteristic belonging within a certain range.

Group occupational risk is calculated as per results obtained via epidemiologic research and is based on comparing probability of occupational and work-related diseases caused by exposure to occupational factors. To solve these tasks, it is necessary to create a test group and a reference one. Since exposure to occupational factors and factors related to labor process are determined for specific workplaces, it is assumed that all workers who work at these workplaces are exposed to factors that are thought to exist at them.

Work performed under exposure to occupational factors and ones related to labor process that differ from optimal levels is a basic criterion for including workers into test groups. In order to properly take combined exposure to occupational factors into account, a test group can be divided into sub-groups that are characterized with similar sets of occupational factors.

Work performed under exposure to occupational factors and factors related to labor process that are within permissible levels is a basic criterion for including workers into reference groups. Age and working experience of workers included into test and reference groups should be comparable with no authentic discrepancies between them.

A list of probable occupational diseases (OD) and work-related diseases (WRD) is determined for each factor; these diseases should be relevant to specific occupational factors and factors related to labor process.

After authentic cause-and-effect relations have been established as per epidemiologic criteria ( $R R \geq 1.5$ ); a number of diagnosed occupational diseases and work-related diseases is revealed in both groups, and frequency (probability) of each disease is calculated as per the following formula:

$$
\mathrm{w}_{\mathrm{OD}(\mathrm{WRD})}=\frac{n_{\mathrm{OD}(\mathrm{WRD})}}{N},
$$

where $\mathrm{w}_{\mathrm{OD}}$ (WRD) is OD (WRD) frequency; $n_{\Pi 3}$ is a number of workers in a group who have OD (WRD);

$N$ is an overall number of workers in a group.

Then additional frequency (probability) of occupational diseases and work-related diseases is determined for a test group:

$$
w_{\mathrm{OD}(\mathrm{WRD})}^{\mathrm{add}}=w_{\mathrm{OD}(\mathrm{WRD})}^{\mathrm{test}}-w_{\mathrm{OD}(\mathrm{WRD})}^{\mathrm{ref}},
$$

where $w_{\mathrm{OD}}^{\text {add }}$ (WRD) is additional frequency (probability) of occupational diseases and work-related diseases in a test group;

$$
w_{\mathrm{OD}(\mathrm{WRD})}^{\text {test }}-\text { is frequency (probability) of }
$$
occupational diseases and work-related diseases in a test group;

$w_{\mathrm{OD} \text { (WRD) }}^{\text {ref }}$ is additional frequency (probability) of occupational diseases and workrelated diseases in a reference group.

Since workers are exposed to multi-factor combined influence exerted by occupational factors and factors related to labor process, it is quite possible that occupational diseases and work-related ones will develop in them simultaneously. Such a situation may result in aggravated clinical course of any disease. In this 
case we should calculate frequency of simultaneous OD and WRD development in test and reference groups:

$$
w_{\mathrm{OD}, \mathrm{WRD}}=\frac{n_{\mathrm{OD}, \mathrm{WRD}}}{N},
$$

where $w_{\mathrm{OD}, \mathrm{WRD}}$ is frequency of simultaneous OD and WRD development;

$n_{\mathrm{OD}, \mathrm{WRD}}$ is number of workers in a group with simultaneously diagnosed OD and WRD;

$N$ is an overall number of workers in a group.

$$
w_{\mathrm{OD}, \mathrm{WRD}}^{\mathrm{add}}=w_{\mathrm{OD}, \mathrm{WRD}}^{\mathrm{test}}-w_{\mathrm{OD}, \mathrm{WRD}}^{\mathrm{ref}},
$$

where $w_{\mathrm{OD} \text {, wRD }}^{\text {add }}$ is additional frequency (probability) of simultaneous occupational diseases and work-related diseases development in a test group;

$w_{\mathrm{OD}, \text { WRD }}^{\text {test }}$ is frequency (probability) of simultaneous occupational diseases and workrelated diseases development in a test group;

$w_{\mathrm{OD}, \text { WRD }}^{\text {ref }}$ is frequency (probability) of simultaneous occupational diseases and work-related diseases development in a reference group.

Occupational risks caused by exposure to examined occupational factors and related to occupational diseases and work-related ones $\left(R_{\mathrm{OD}(\mathrm{WRD})}^{\mathrm{occ}}\right)$ are calculated as per the following formula taking gravity of these diseases into account $\left(g_{\mathrm{OD}(\mathrm{WRD})}\right)$

$$
R_{\mathrm{OD}(\mathrm{WRD})}^{\mathrm{occ}}=w_{\mathrm{OD}(\mathrm{WRD})}^{\mathrm{add}} \cdot g_{\mathrm{OD}(\mathrm{WRD})},
$$

And these occupational risks caused by exposure to examined occupational factors and related to simultaneously occurring occupational diseases and work-related ones $\left(R_{\mathrm{OD}(\mathrm{WRD})}^{\mathrm{occ}}\right)$ are calculated taking combined gravity of these diseases into account $\left(g_{\text {OD, WRD }}\right)$

$$
R_{\mathrm{OD}, \mathrm{WRD}}^{\mathrm{occ}}=w_{\mathrm{OD}, \mathrm{WRD}}^{\mathrm{add}} \cdot g_{\mathrm{OD}, \mathrm{WRD}} \cdot
$$

Combine gravity of occupational diseases and work-related ones in case they develop simultaneously $\left(g_{\mathrm{OD}, \mathrm{WRD}}\right)$ is calculated as per the following formula

$$
g_{\mathrm{OD}, \mathrm{WRD}}=g_{\mathrm{OD}}+g_{\mathrm{WRD}}-g_{\mathrm{OD}} \cdot g_{\mathrm{WRD}},
$$

where $g_{\mathrm{OD}}$ is gravity of occupational diseases;

$g_{\text {WRD }}$ is gravity of work-related diseases.

Individual occupational health risk is assessed as per results obtained via mathematical modeling that shows dependence between probability of negative responses and working conditions, age, and working experience (creation of logistic regression models). These models (formula 8) that quantitatively determine dependence for a probability of a negative response (occupational or workrelated disease) under exposure to occupational factors and factors related to labor process taking into account intensity of an influencing factor, workers' age and working experience are built for each examined group. Parameters used in a mathematical model are determined with the least square procedure and specific software for statistic data analysis (for example, Statistica 6.0). Parameters authenticity and model validity are assessed basing on one-factor dispersion analysis as per Fischer's test.

$$
p_{1}=\frac{1}{1+e^{-\left(b_{0}+b_{1} X_{1} \cdot x_{2}+b_{2} X_{3}\right)}},
$$

where $p_{1}$ is a probability of a negative response (occupational or work-related disease);

$x_{1}$ is a level of exposure to noise factor, dBA;

$x_{2}$ is working experience, years;

$x_{3}$ is age, years;

$b_{0}, b_{1}, b_{2}$ are parameters used in a mathematical model.

Obtained levels of occupational risks are considered deterministic values that are assessed (assigned into a specific risk category) according to a suggested scale (Table 1).

But still, it is advisable to consider whether it is possible to apply approaches based on simultaneous use of set theory and mathematical logic when it comes to assessing occupational risks categories given multifactor combined exposure to occupational factors and factors related to labor process that are able to cause both occupational and work-related diseases. 
Table 1

Table 2

A scale for assessing occupational risks levels

\begin{tabular}{|c|c|}
\hline $\begin{array}{c}\text { Occupational } \\
\text { risks levels }\end{array}$ & $\begin{array}{c}\text { Occupational } \\
\text { risk category }\end{array}$ \\
\hline Less than $1 \cdot 10^{-4}$ & Negligible risk \\
\hline $1 \cdot 10^{-4}-1 \cdot 10^{-3}$ & Low risk \\
\hline $1 \cdot 10^{-3}-1 \cdot 10^{-2}$ & Moderate risk \\
\hline $1 \cdot 10^{-2}-3 \cdot 10^{-2}$ & Average risk \\
\hline $3 \cdot 10^{-2}-1 \cdot 10^{-1}$ & High risk \\
\hline $1 \cdot 10^{-1}-3 \cdot 10^{-1}$ & Very high risk \\
\hline $3 \cdot 10^{-1}-1$ & Extremely high risk \\
\hline
\end{tabular}

A basic tool used to implement this procedure is determining whether deterministic risk assessments belong to specific trapezoid fuzzy intervals that characterize risk categories. A trapezoid fuzzy interval is considered as a normal fuzzy interval and its membership function may be set with a trapezoid function.

To determine exactly whether deterministic occupational risk values belong within its categories, we suggest using a scale showing trapezoid fuzzy numbers built on the basis of

A scale showing trapezoid fuzzy numbers for assessing occupational risk levels

\begin{tabular}{|c|c|}
\hline $\begin{array}{l}\text { Trapezoid fuzzy numbers } \\
\text { (four numbers that set } \\
\text { a trapezoid number) }\end{array}$ & $\begin{array}{l}\text { Occupational } \\
\text { risk category }\end{array}$ \\
\hline $0,0,0.00005,0.00033$ & Negligible risk \\
\hline $\begin{array}{c}(0.00005,0.00033,0.00078, \\
0.00325\end{array}$ & Low risk \\
\hline $\begin{array}{c}0.00078,0.00325,0.0775 \\
0.015\end{array}$ & Moderate risk \\
\hline $0.0775,0.015,0.025,0.0475$ & Average risk \\
\hline $0.025,0.0475,0,0825,0.15$ & High risk \\
\hline $0.0825,0.15,0.25,0.53$ & Very high risk \\
\hline $0.25,0.53,1,1$ & Extremely high risk \\
\hline
\end{tabular}

deterministic scale showing assessment of occupational risk levels (Table 2, Figure).

Trapezoid fuzzy numbers allow determining whether a value belongs within a certain risk category, and if it belongs to the smaller base of a trapezoid number then a degree to its belonging to a relevant risk category is equal to 1 ; in other cases a degree of belonging is determined with a membership function.

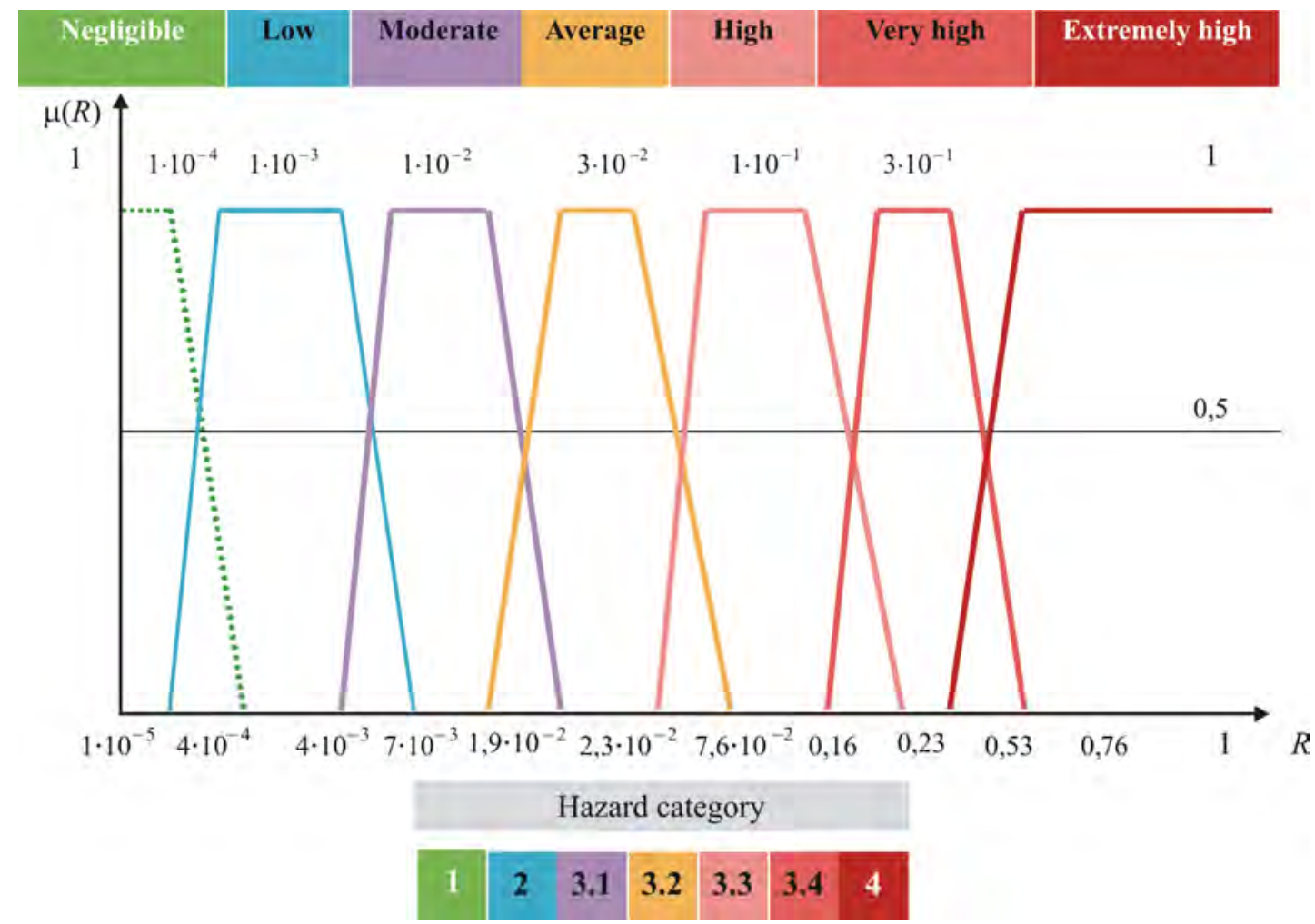

Figure. Graphic image of a scale showing trapezoid fuzzy numbers for assessing occupational risk levels 
A basic tool for implementing this procedure is determining a membership function of a trapezoid fuzzy number which allows estimating whether deterministic risk assessments belong to a specific risk category. In general it is given as follows:

$$
\mu(x)= \begin{cases}0, & \text { if } x<a_{1} \\ \frac{x-a_{1}}{a_{2}-a_{1}}, & \text { if } a_{1} \leq x<a_{2} \\ 1, & \text { if } a_{2} \leq x \leq a_{3} \\ \frac{x-a_{4}}{a_{3}-a_{4},}, & \text { if } a_{3}<x \leq a_{4} \\ 0, & \text { if } x>a_{4}\end{cases}
$$

It is important to note that a point where two trapezoids cross means that a risk assessment equally belongs to both relevant risk categories.

Taking into account all the estimates obtained for the membership function of a trapezoid fuzzy number, adjusted risk levels $\left(S R_{k}\right)$ are determined as per following formula:

$$
S R_{k}=\sum_{i} q_{i} \cdot \mu_{k i}\left(R_{\mathrm{OD}(\mathrm{WRD})}^{\mathrm{occ}}\right), k=1,2,3,4,5,6,(10)
$$

where $q_{i}$ is a weighted contribution made by risk category $i$ into overall risk level; cance.

$k$ is a degree of risk category signifi-

A weighted contribution made by risk category i into overall risk level $\left(q_{i}\right)$ is calculated with Fishburne's formula:

$$
q_{i}=2(n-i+1) /(n-1) n, i=1,2,3,4,5,6
$$

where $\mathrm{n}$ is a number of risk categories.

Adjusted risk levels are considered as a basis for substantiating activities aimed at occupational risk management according to its category.

The suggested approaches were tested in assessing occupational risks for workers employed at a non-ferrous metallurgy enterprise. In-plant noise was taken as a priority adverse occupational factor. Apart from it, workers' health can be also potentially influenced by such adverse occupational factors as dusts and labor hardness.

Taking working conditions into account, we created the following workers' groups. The test group was made up of 111 workers (100\% males) exposed to in-plant noise equal to $85 \mathrm{dBA}$, their average age was $35.63 \pm 3.38$ and their average working experience was equal to $11.40 \pm 6.38$ years.

The reference group included 47 workers who were not exposed to in-plane noise $(100 \%)$ males but their working conditions were similar to those of the test group. Average age was $37.36 \pm 1.52$ and average working experience was equal to $12.85 \pm 2.30$ years.

Basing on available data on prevailing damage to target organs occurring due to contacts with adverse occupational factors we substantiated and implemented a program for workers' medical examinations that included an assessment, clinical examination, and laboratory tests in the following spheres:

- a clinical examination aimed at assessing the circulatory system and hearing organs;

- diagnostics of hearing disorders with noise etiology with whisper acumetry and audiometric hearing examination (pure-tone threshold audiometry performed with «Biomedilen» 2A-02 audiometer);

- an ultrasound examination of vasomotor functions performed by brachial artery endothelium in endothelium-dependent vasodilatation test as per a procedure described and modified by D.S. Celermajer et al. (1992); the procedure was performed with «Toshiba VIAMO» ultrasound expert scanner (Japan) with $7 \mathrm{~Hz}$ linear device;

- an ultrasound examination of extracranial sections in brachiocephalic arteries performed as per a conventional procedure with TOSHIBA APLIOXG, model SSA-790A, ultrasound diagnostic system (Japan) with 10-14 Hz linear device;

- laboratory tests performed with unified hematologic, biochemical, and ELISA procedures that allowed estimating functional state of target organs. Laboratory parameters obtained for examined workers from the reference group were taken as assessment criteria 
for estimating whether laboratory parameters obtained for the test group had any deviations from normal values.

Preliminary diagnosis «sensorineural hearing loss of the $1^{\text {st }}$ and $2^{\text {nd }}$ degree» was put as per results obtained via clinical examination for 13 workers from the test group and 1 worker from the reference one. «Essential [primary] hypertension» was diagnosed in 14 workers from the test group and 3 workers from the reference one. 3 workers from the test group had both sensorineural hearing loss and arterial hypertension.

Sensorineural hearing loss was considered to be an occupational disease in this research work. Epidemiologic assessment of a causeand-effect relation between arterial hypertension and working conditions revealed that relative risk parameter (RR) amounted to 5.17 (confidence intervals were 1.52-17.52). It allows considering arterial hypertension to be a work-related disease.

Additional probability that sensorineural hearing loss might occur amounted to 0.095 for workers from the test group; the same parameter in this group amounted to 0.062 for arterial hypertension. Occupational risk related to sensorineural hearing loss with its gravity being equal to 0.32 amounted to $3.1 \cdot 10^{-2}$ (high risk); arterial hypertension with its gravity being equal to $0.25,1.6 \cdot 10^{-2}$ (average risk). Occupational risk related to combined sensorineural hearing loss and arterial hypertension with the gravity being equal to 0.49 amounted to $0.004-4 \cdot 10^{-3}$ (moderate risk).

We determined a membership function of a trapezoid fuzzy number for all levels of occupational risks; it allowed revealing that it was equal to 1 in all cases and adjusted occupational risk levels corresponded to those determined as per results obtained via epidemiologic research.

Funding. The research was not granted any sponsor support.

Conflict of interests. The authors declare there is no any conflict of interests.

\section{References}

1. Topilin A.V. Russia's labor potential: demographic and socio-economic problems of formation and utilization. Vestnik Rossiiskoi akademii nauk, 2019, vol. 89, no. 7, pp. 736-744 (in Russian).

2. Izmerov N.F. Occupational assessment and management are the basis of prophylaxis in occupational medicine. Gigiena i sanitariya, 2006, no. 5, pp. 14-16 (in Russian).

3. Izmerov N.F., Simonova N.I., Nizyaeva I.V. Study and analysis of occupational risk profile. Meditsina truda i promyshlennaya ekologiya, 2015, no. 9, pp. 60-61 (in Russian).

4. Zheglova A.V. Personalized occupational risk and longevity. Meditsina truda i promyshlennaya ekologiya, 2019, vol. 59, no. 9, pp. 627 (in Russian).

5. Simonova N.I. Assessment of individual occupational risk. Okhrana truda i tekhnika bezopasnosti na promyshlennykh predpriyatiyakh, 2015, no. 3, pp. 15-22 (in Russian).

6. Prokopenko L.V., Kur'erov N.N., Lagutina A.V., Pochtareva E.S. Identification and assessment of the group redundant (attributive) risk of hearing loss from noise. Meditsina truda i promyshlennaya ekologiya, 2019, vol. 59, no. 4, pp. 212-218 (in Russian).

7. Chebotarev A.G., Gibadulina I.Yu. Occupational risks, respiratory pathology of mine workers operating self-propelled vehicles with diesel engines. Gornaya promyshlennost', 2016, no. 2 (126), pp. 75 (in Russian).

8. Valeeva E.T., Bakirov A.B., Karimova L.K. Occupational risks for chemical workers' health.Vestnik Rossiiskogo gosudarstvennogo meditsinskogo universiteta, 2013, no. 5-6, pp. 124-128 (in Russian).

9. Meshchakova N.M., Rukavishnikov V.S. Occupational loss risk for the health state in employees of modern sulfate cellulose production. Byulleten' Vostochno-Sibirskogo nauchnogo tsentra Sibirskogo otdeleniya Rossiiskoi akademii meditsinskikh nauk, 2011, no. 3-2 (79), pp. 123-128 (in Russian).

10. Setko N.P., Bulycheva E.V. Modern aspects of estimation of professional risk and health factors of working enterprises of the petrochemical industry (review). Orenburgskii meditsinskii vestnik, 2017, vol. 5, no. 3 (19), pp. 4-9 (in Russian). 
11. Klimova I.V. Application of methods of fuzzy modeling for solving problems of technosphere safety. Gornyi informatsionno-analiticheskii byulleten' (nauchno-tekhnicheskii zhurnal), 2019, no. S7, pp. 87-98 (in Russian).

12. Zade L. Ponyatie lingvisticheskoi peremennoi i ego primenenie k prinyatiy u priblizhennykh reshenii [Linguistic variable and its application in finding approximate solutions]. Moscow, Mir Publ., 1976, 166 p. (in Russian).

13. Korkmaz H., Canayaz E., Birtane S., Altıkardeş A. Fuzzy logic based risk assessment system giving individualized advice for metabolic syndrome and fatal cardiovascular diseases. Technol Health Care, 2019, vol. 27, no. 1, pp. 59-66. DOI: 10.3233/THC-199007

14. Farzandipour M., Nabovati E., Saeedi S., Fakharian E. Fuzzy decision support systems to diagnose musculoskeletal disorders: A systematic literature review. Comput Methods Programs Biomed, 2018, no. 163, pp. 101-109. DOI: 10.1016/j.cmpb.2018.06.002

15. Miranda G.H.B., Felipe J.C. Computer-aided diagnosis system based on fuzzy logic for breast cancer categorization. Computers in Biology and Medicine, 2015, vol. 64, no. 1, pp. 334-346. DOI: 10.1016/j.compbiomed.2014.10.006

16. Alonso A.L., Rosas-Jaimes O.A., Suarez-Cuenca J.A. Fuzzy Logic Assisted Diagnosis for Atherogenesis Risk. IFAC Proceedings Volumes, 2013, vol. 46, no. 31, pp. 244-248.

17. Zimmerman H.-J. Fuzzy Set Theory and its Applications. Dordrecht, Kluwer Academic Publishers Publ., 1996, 315 p.

Zaitseva N.V., Shur P.Z., Alekseev V.B., Savochkina A.A., A.I. Savochkin, Khrushcheva E.V. Methodical approaches to assessing categories of occupational risk predetermined by various health disorders among workers related to occupational and labor process factors. Health Risk Analysis, 2020, no. 4, pp. 24-31. DOI: 10.21668/health.risk/2020.4.03.eng

Received: 10.09 .2020

Accepted: 08.12.2020

Published: 30.12 .2020 